\title{
Regional retinal blood flow reduction following half fundus photocoagulation treatment
}

\author{
Naoki Fujio, Gilbert T Feke, Douglas G Goger, J Wallace McMeel
}

\begin{abstract}
Regional changes in retinal blood flow following inferior and subsequent superior argon laser half fundus photocoagulation treatment were measured in six diabetic patients with advanced retinopathy. Centreline blood velocity, vessel diameter, and blood flow in major inferior and superior temporal retinal arteries were measured at baseline and following each treatment using the bidirectional laser Doppler technique and monochromatic fundus photography. Inferior fundus laser treatment produced a significant blood flow decrease in inferior temporal arteries ranging from $60 \%$ to $78 \%$. Blood flow changes in superior temporal arteries were not significant, ranging from $-7 \%$ to $+14 \%$. Subsequent superior fundus laser treatment produced a significant blood flow decrease in superior temporal arteries ranging from $50 \%$ to $66 \%$. Subsequent blood flow changes in inferior temporal arteries were not significant, ranging from $-19 \%$ to $+21 \%$. The results indicate that regional laser treatment produces a regional reduction in retinal blood flow, consistent with measurements of preretinal and intraretinal oxygen tension which have indicated increases in oxygen over photocoagulated regions.

(BrF Ophthalmol 1994; 78: 335-338)
\end{abstract}

It has been shown that panretinal photocoagulation (PRP) is effective in inducing regression of retinal neovascularisation in patients with proliferative diabetic retinopathy. ${ }^{1-4} \mathrm{~A}$ number of clinical and experimental studies have been aimed at elucidating the underlying mechanisms for this effect. Experimental studies by Molnar et $a l,{ }^{5}$ Alder $e t a l,{ }^{6}$ and Novack $e t a l^{7}$ have shown that there are local increases in preretinal or intraretinal oxygen tension in regions overlying the photocoagulated outer retina. A similar result was reported in a clinical study by Stefánsson $e t a l .^{8}$ These local increases in oxygen tension are probably responsible for the retinal vasoconstriction that has been observed clinically following photocoagulation treatment. ${ }^{9-14}$
Wilson $e t a l^{13}$ suggested that it is vascular narrowing which is primarily responsible for inducing the regression of neovascularisation: thin, atrophic retinal vessels being associated with involuted or inactive neovascular disease, and dilated vessels with persistent or progressive disease.

A reduction in retinal blood flow accompanies retinal vasoconstriction. Grunwald $e t a l^{1214}$ and Patel et al $^{15}$ have shown decreases in retinal blood flow in diabetic patients following full fundus PRP. In this study, we sought to determine whether half fundus PRP produces a regional reduction in retinal blood flow that would be consistent with the findings of the previously reported oxygen tension measurements.

\section{Patients and methods}

Subjects for the study were six diabetic patients who had been judged to require PRP treatment in at least one eye. Each patient had received a complete eye examination including indirect ophthalmoscopy, stereo colour fundus photography, and fluorescein angiography. The baseline characteristics of the patients including a summary of the level of retinopathy in the eye studied are given in Table 1.

The procedures performed in the study followed the tenets of the Declaration of Helsinki, and were approved by the Schepens Eye Research Institute human studies committee. Written informed consent was obtained from each patient.

At visit 1 , immediately following baseline laser Doppler measurements, each patient received argon laser treatment in the inferior fundus of the eye studied. Laser burns were applied from outside the vascular arcade to the mid-periphery. Laser power was 100 to $300 \mathrm{~mW}$, exposure time was $0 \cdot 2$ seconds, and burn diameters ranged from 100 to $500 \mu \mathrm{m}$. At visit 2, again immediately following laser Doppler measurements, each patient was treated in the superior fundus in the same fashion as in the inferior fundus. The final laser Doppler measurements were obtained at visit 3. Table 1 shows the number of laser burns
The Schepens Eye Research Institute and Harvard Medical School, Boston, USA

N Fujio

G T Feke

D G Goger

J W McMeel

Correspondence to: Gilbert T Feke, PhD, The Schepens Eye Research Institute, 20 Staniford Street, Boston, MA 02114, USA

Accepted for publication 24 November 1993
Table 1 Patient characteristics at baseline and treatment procedures

\begin{tabular}{|c|c|c|c|c|c|c|c|c|c|c|c|}
\hline \multirow[b]{2}{*}{ Patient } & \multirow{2}{*}{$\begin{array}{l}\text { Age } \\
\text { (years) }\end{array}$} & \multirow[b]{2}{*}{ Sex } & \multirow[b]{2}{*}{ Diagnosis } & \multirow{2}{*}{$\begin{array}{l}\text { Diabetes } \\
\text { duration } \\
\text { (years) }\end{array}$} & \multirow{2}{*}{$\begin{array}{l}\text { Visual } \\
\text { acuity }\end{array}$} & \multirow{2}{*}{$\begin{array}{l}I O P \\
(m m H g)\end{array}$} & \multirow{2}{*}{$\begin{array}{l}\text { Retinopathy } \\
\text { (eye) }\end{array}$} & \multicolumn{2}{|c|}{ Laser burns } & \multicolumn{2}{|c|}{$\begin{array}{l}\text { Elapsed times between } \\
\text { visits (weeks) }\end{array}$} \\
\hline & & & & & & & & Inferior & Superior & $1-2$ & $2-3$ \\
\hline $\begin{array}{l}1 \\
2 \\
3 \\
4 \\
5 \\
6\end{array}$ & $\begin{array}{l}38 \\
45 \\
25 \\
63 \\
26 \\
36\end{array}$ & $\begin{array}{l}\mathbf{F} \\
\mathbf{M} \\
\mathbf{M} \\
\mathbf{M} \\
\mathbf{F} \\
\mathbf{F}\end{array}$ & $\begin{array}{l}\text { IDDM } \\
\text { IDDM } \\
\text { IDDM } \\
\text { NIDDM } \\
\text { IDDM } \\
\text { IDDM }\end{array}$ & $\begin{array}{l}34 \\
34 \\
17 \\
12 \\
15 \\
15\end{array}$ & $\begin{array}{l}20 / 20 \\
20 / 20 \\
20 / 20 \\
20 / 40 \\
20 / 40 \\
20 / 25\end{array}$ & $\begin{array}{l}18 \\
14 \\
21 \\
15 \\
13 \\
19\end{array}$ & $\begin{array}{l}\text { NVE (L) } \\
\text { NVE (L) } \\
\text { NPA (R) } \\
\text { NPA (L) } \\
\text { NVD (R) } \\
\text { NVE (L) }\end{array}$ & $\begin{array}{l}503 \\
622 \\
800 \\
412 \\
500 \\
600\end{array}$ & $\begin{array}{l}519 \\
595 \\
751 \\
606 \\
589 \\
662\end{array}$ & $\begin{array}{l}3 \\
3 \\
4 \\
4 \\
2 \\
5\end{array}$ & $\begin{array}{r}6 \\
5 \\
5 \\
4 \\
10 \\
16\end{array}$ \\
\hline
\end{tabular}

IDDM = insulin-dependent diabetes mellitus; NIDDM = non-insulin-dependent diabetes mellitus; NVD=neovascularisation at the disc; $\mathrm{NVE}=$ neovascularisation elsewhere; $\mathrm{NPA}=$ non-perfusion areas; $\mathrm{L}=$ left eye; $\mathrm{R}=$ right eye. 
applied in each half fundus, as well as the times between visits 1 and 2 and visits 2 and 3 .

Before laser Doppler testing at each visit, the patient's pupils were dilated with $1 \%$ tropicamide. Monochromatic $(575 \mathrm{~nm})$ fundus photographs were taken of the eye chosen for study. Intraocular pressure was measured by applanation tonometry. The methodology of our application of the laser Doppler technique to measurement of centreline blood velocity in retinal arteries has been previously described..$^{16}$ Our projection micrometry technique for measurement of arterial diameters using monochromatic photographs has also been previously described. ${ }^{18}$

Blood flow rate in an individual retinal artery -was calculated as

\section{flow $=\overline{\mathrm{V}} \times$ area $/ 2$}

where $\bar{V}$ is the time average of the centreline blood velocity during the cardiac cycle, and area is the cross sectional area of the retinal artery at the laser Doppler measurement site. ${ }^{19}$ The area

Table 2 Centreline blood velocity measured in inferior (IT) and superior (ST) temporal retinal arteries at visits $1,2,3$

\begin{tabular}{rlllll}
\hline & \multicolumn{3}{l}{ Velocity measurements $(\mathrm{cm} / \mathrm{s})$} & Percentage change & $\begin{array}{l}\text { Percentage change } \\
\text { visits 2-3 }\end{array}$ \\
\cline { 2 - 4 } Patient No & Visit 1 & Visit 2 & Visit 3 & & \\
\hline IT: & $6 \cdot 3$ & $2 \cdot 0$ & $2 \cdot 5$ & -69 & 25 \\
1 & $6 \cdot 4$ & $2 \cdot 6$ & $2 \cdot 4$ & -59 & -8 \\
2 & $9 \cdot 3$ & $2 \cdot 2$ & $2 \cdot 1$ & -76 & -5 \\
3 & $8 \cdot 1$ & $3 \cdot 8$ & $3 \cdot 0$ & -53 & 12 \\
4 & $7 \cdot 2$ & $2 \cdot 5$ & $2 \cdot 8$ & -65 & -44 \\
5 & $4 \cdot 7$ & $4 \cdot 5$ & $2 \cdot 5$ & -4 & -45 \\
ST: & $8 \cdot 2$ & $8 \cdot 7$ & $4 \cdot 8$ & 6 & -50 \\
1 & $6 \cdot 2$ & $6 \cdot 4$ & $3 \cdot 2$ & 2 & -63 \\
2 & $7 \cdot 7$ & $7 \cdot 9$ & $2 \cdot 9$ & 3 & -53 \\
3 & $5 \cdot 3$ & $5 \cdot 5$ & $2 \cdot 6$ & 4 & \\
4 & & & & &
\end{tabular}

Table 3 Vessel diameter at the laser Doppler measurement site along inferior (IT) and superior (ST) temporal retinal arteries at visits $1,2,3$

\begin{tabular}{|c|c|c|c|c|c|}
\hline \multirow[b]{2}{*}{ Patient No } & \multicolumn{3}{|c|}{ Vessel diameter $(\mu m)$} & \multirow{2}{*}{$\begin{array}{l}\text { Percentage change } \\
\text { visits } 1-2\end{array}$} & \multirow{2}{*}{$\begin{array}{l}\text { Percentage chang } \\
\text { visits 2-3 }\end{array}$} \\
\hline & Visit I & Visit 2 & Visit 3 & & \\
\hline \multicolumn{6}{|l|}{ IT: } \\
\hline $\mathrm{i}$ & 143 & 138 & 136 & -3 & -1 \\
\hline 2 & 148 & 136 & 136 & -8 & 0 \\
\hline 3 & 148 & 159 & 151 & 7 & -5 \\
\hline 4 & 105 & 97 & 98 & -8 & 1 \\
\hline 5 & 123 & 125 & 124 & 2 & -1 \\
\hline \multicolumn{6}{|l|}{ ST: } \\
\hline 1 & 119 & 120 & 113 & 1 & -6 \\
\hline 2 & 126 & 122 & 111 & -3 & -9 \\
\hline 3 & 143 & 151 & 141 & 6 & -7 \\
\hline 4 & 105 & 100 & 96 & -5 & -4 \\
\hline 6 & 118 & 114 & 113 & -3 & -1 \\
\hline
\end{tabular}

Table 4 Blood flow measured in inferior (IT) and superior (ST) temporal retinal arteries at visits $1,2,3$

\begin{tabular}{|c|c|c|c|c|c|}
\hline \multirow[b]{2}{*}{ Patient No } & \multicolumn{3}{|c|}{ Blood flow measurements $(\mu \mathrm{l} / \mathrm{min})$} & \multirow{2}{*}{$\begin{array}{l}\text { Percentage change } \\
\text { visits 1-2 }\end{array}$} & \multirow{2}{*}{$\begin{array}{l}\text { Percentage change } \\
\text { visits 2-3 }\end{array}$} \\
\hline & Visit 1 & Visit 2 & Visit 3 & & \\
\hline $\begin{array}{r}\text { IT: } \\
1 \\
2 \\
3 \\
4 \\
5\end{array}$ & $\begin{array}{l}30 \cdot 1 \\
33 \cdot 0 \\
48 \cdot 0 \\
21 \cdot 0 \\
25 \cdot 7\end{array}$ & $\begin{array}{r}9 \cdot 0 \\
11 \cdot 3 \\
13 \cdot 1 \\
8 \cdot 4 \\
9 \cdot 2\end{array}$ & $\begin{array}{r}10.9 \\
10.5 \\
11.3 \\
6.8 \\
10.1\end{array}$ & $\begin{array}{l}-73 \\
-66 \\
-78 \\
-60 \\
-64\end{array}$ & $\begin{array}{r}21 \\
-7 \\
-14 \\
-19 \\
10\end{array}$ \\
\hline $\begin{array}{r}\text { ST: } \\
1 \\
2 \\
3 \\
4 \\
6\end{array}$ & $\begin{array}{l}15 \cdot 7 \\
30 \cdot 7 \\
29 \cdot 9 \\
20 \cdot 0 \\
17 \cdot 2\end{array}$ & $\begin{array}{l}15 \cdot 3 \\
30 \cdot 5 \\
34 \cdot 1 \\
18 \cdot 6 \\
16 \cdot 8\end{array}$ & $\begin{array}{r}7.5 \\
13.9 \\
15.0 \\
6.3 \\
7.8\end{array}$ & $\begin{array}{r}-3 \\
-1 \\
14 \\
-7 \\
-2\end{array}$ & $\begin{array}{l}-50 \\
-54 \\
-56 \\
-66 \\
-54\end{array}$ \\
\hline
\end{tabular}

was calculated from the arterial diameter assuming a circular cross section.

The arteries chosen for measurement had relatively straight segments that were sufficiently distant from adjacent vessels. Measurement sites were between the disc margin and the first bifurcation. Both an inferior and a superior temporal artery were measured in patients $1-4$. Only an inferior temporal artery was measured in patient 5 , and only a superior temporal artery was measured in patient 6 .

Data were analysed using non-parametric statistical methods. These included the Friedman two way analysis of variance (ANOVA), the Wilcoxon signed rank test, and Spearman rank correlation analysis. A p value of 0.05 or less was considered statistically significant.

\section{Results}

The centreline blood velocity, the arterial diameter at the laser Doppler measurement site, and the blood flow measured at each visit are shown in Tables 2-4. Between visit 1 and visit 2, the decreases in centreline blood velocity in the inferotemporal arteries ranged from $53 \%$ to $76 \%$, while the change in the superotemporal arteries ranged from $-4 \%$ to $+6 \%$. Between visit 2 and visit 3 , the changes in the inferotemporal arteries ranged from $-21 \%$ to $+25 \%$, while the decreases in the superotemporal arteries ranged from $44 \%$ to $63 \%$. Percentage changes in arterial diameter were much smaller. Decreases in inferotemporal diameters between visit 1 and visit 2 were seen in three vessels, and decreases in superotemporal diameters between visit 2 and visit 3 were seen in all five vessels.

Between visit 1 and visit 2 , the decreases in blood flow in the inferotemporal arteries ranged from $60 \%$ to $78 \%$, while the changes in superotemporal arteries ranged from $-7 \%$ to $+14 \%$. Between visit 2 and visit 3, the changes in the inferotemporal arteries ranged from $-19 \%$ to $+21 \%$, while the decreases in blood flow in the superotemporal arteries ranged from $50 \%$ to $66 \%$.

Analysis of the results using Friedman two way ANOVA showed statistically significant differences in blood velocity $(p=0.022)$ and blood flow ( $p=0.022)$ in inferotemporal arteries, and statistically significant differences in blood velocity $(p=0.015)$, arterial diameter $(p=0.022)$, and blood flow $(p=0.015)$ in superotemporal arteries. Table 5 shows the results of the statistical comparisons using the Wilcoxon signed rank test. The centreline blood velocity and

Table 5 Statistical comparisons using Wilcoxon signed rank test

\begin{tabular}{|c|c|c|c|}
\hline $\begin{array}{l}\text { Inferior temporal artery } \\
\text { comparison }\end{array}$ & Visits I-2 & Visits 1-3 & Visits 2-3 \\
\hline $\begin{array}{l}\text { Blood velocity } \\
\text { Arterial diameter } \\
\text { Blood flow }\end{array}$ & $\begin{array}{l}p=0.04 \\
\text { ns } \\
p=0.04\end{array}$ & $\begin{array}{l}p=0.04 \\
\text { ns } \\
p=0.04\end{array}$ & $\begin{array}{l}\text { ns } \\
\text { ns } \\
\text { ns }\end{array}$ \\
\hline $\begin{array}{l}\text { Superior temporal artery } \\
\text { comparison }\end{array}$ & Visits $1-2$ & Visits $1-3$ & Visits 2-3 \\
\hline $\begin{array}{l}\text { Blood velocity } \\
\text { Arterial diameter } \\
\text { Blood flow }\end{array}$ & $\begin{array}{l}\text { ns } \\
\text { ns } \\
\text { ns }\end{array}$ & $\begin{array}{l}p=0.04 \\
p=0.04 \\
p=0.04\end{array}$ & $\begin{array}{l}p=0.04 \\
p=0.04 \\
p=0.04\end{array}$ \\
\hline
\end{tabular}


blood flow measured at visit 1 in inferotemporal arteries were significantly $(p=0.04)$ higher compared with velocity and flow measured at the same sites at visits 2 and 3 . The velocity, arterial diameter, and blood flow measured at visits 1 and 2 in superotemporal arteries were significantly $(p=0.04)$ higher compared with the velocity, diameter, and blood flow measured at the same sites at visit 3 .

Visual acuity was unchanged in each patient at each visit. Intraocular pressures measured in each patient at each visit ranged from 10 to 22 $\mathrm{mm} \mathrm{Hg}$. There were no systematic changes in intraocular pressure (IOP) related to the laser treatments. Spearman rank correlation analysis was used to determine if the changes in arterial blood flow were related to age, IOP, duration of diabetes, number of laser burns, or elapsed time between measurements. None of these parameters showed statistical significance.

All six patients showed improvement in their diabetic eye disease at visit 3 compared with their baseline status at visit 1 . There was regression of neovascularisation in the four patients having new vessels at baseline.

\section{Discussion}

Our results confirm that the effect of half fundus panretinal photocoagulation (PRP) treatment on retinal blood flow is indeed regional. This finding is consistent with the results of previously reported experimental ${ }^{5-7}$ and clinical ${ }^{8}$ studies of regional variation in preretinal or intraretinal oxygen tension in eyes that underwent regional PRP.

Interpretation of these findings may lead to a firm basis for understanding the mechanisms responsible for the regression of neovascularisation following PRP. As described by Weiter and Zuckerman, ${ }^{20}$ PRP destroys the high oxygen consuming photoreceptor retinal pigment epithelial complex. Oxygen orginating from the choroidal vasculature is not consumed, and diffuses to the inner retina.

Elevated oxygen tension in the inner retina may have a direct effect on retinal neovascularisation by removing the hypoxic stimulus $^{21}$ or an indirect effect via the vasoconstrictive response. Wilson et $a l^{13}$ measured retinal vessel diameters before and after PRP in eyes with diabetic retinopathy and optic disc neovascularisation. Treatment significantly reduced arterial and venular diameters, and the diameters of the retinal arteries after treatment correlated significantly with the amount of regression in disc neovascularisation. Their results support the idea that persistent or progressive neovascular disease is associated with dilated vessels, while involuted or inactive disease is associated with thin, atrophic vessels.

Modest reductions in retinal vessel diameter can produce large reductions in retinal blood flow. Indeed, the regional reductions in blood flow measured in this study ranged from $50 \%$ to $78 \%$.

As pointed out by Vine, ${ }^{22}$ although PRP proved to be of benefit in the treatment of proliferative diabetic retinopathy, many aspects of laser management have not been established. The optimal amount of initial PRP is unknown, and the criteria for assessing an adequate response to the initial PRP have not been clearly defined. Furthermore, as reported by Kaufman $e t a l,{ }^{23}$ the most important risk factor for severe visual loss despite PRP is persistent disc neovascularisation.

The relation between retinal vasoconstriction and regression of disc neovascularisation reported by Wilson $e t a l^{13}$ strongly suggests that haemodynamic measurements may provide the criteria for assessing the response to PRP. Grunwald $e t a l^{14}$ have already reported that there is an association between the presence or absence of regression of neovascularisation following PRP and an increase or decrease in the retinal blood flow response to systemic hyperoxia. Two questions could be addressed in a prospective study: "is there a minimum threshold of retinal blood flow reduction that is associated with regression of neovascularisation?' and 'What are the minimum thresholds for number and intensity of laser burns associated with the required threshold blood flow reduction?'

This work was supported in part by USPH grant EY01303 from the National Institute of Health and the Massachusetts Lions Eye Research Fund.

The authors wish to thank Yoshihiko Akazawa, MD, and Hiroshi Tagawa, MD, for assistance with the study, and Akitoshi Yoshida, MD, for helpful suggestions and comments.

1 The Diabetic Retinopathy Study Research Group. Preliminary report on effects of photocoagulation therapy. $A m \mathcal{F}$ Ophthalmol 1976; 81: 383-96.

2 The Diabetic Retinopathy Study Research Group. Photocoagulation treatment of proliferative diabetic retinopathy: the second report of diabetic retinopathy study findings. Ophthalmology 1978; 85: 82-106.

3 The Diabetic Retinopathy Study Research Group. Photocoagulation treatment of proliferative diabetic retinopathy. Ophthalmology 1981; 88: 583-600.

4 Early Treatment Diabetic Retinopathy Study Research Group. Early photocoagulation for diabetic retinopathy: Group. Early photocoagulation for diabetic retinopathy:
ETDRS report number 9. Ophthalmology 1991; 98: 767-85.

5 Molnar I, Poitry S, Tsacopoulas M, Gilodi N, Leuenberger PM. Effect of laser photocoagulation on oxygenation of the retina in miniature pigs. Invest Ophthalmol Vis Sci 1985; 26: $1410-4$

6 Alder VA, Cringle SJ, Brown $M$. The effect of regional retinal photocoagulation on vitreal oxygen tension. Invest Ophthalmol Vis Sci 1987 28: 1078-85.

7 Novack RL, Stefánsson E, Hatchell DL. The effect of photocoagulation on the oxygenation and ultrastructure of avascular retina. Exp Eye Res 1990; 50: 289-96.

8 Stefánsson E, Machemer R, de Juan E, McCuen BW, Peterson $\mathrm{J}$. Retinal oxygenation and laser treatment in patients with diabetic retinopathy. Am $\mathcal{f}$ Ophthalmol 1992; 113: 36-8.

9 Koerner F, Fries K, Niesel P, Dubied P. Zur Interpretation der retinalen Kreislaufzeiten bei der diabetischen Retinopathie vor und nach Photokoagulation. Klin Monatsbl Augenheilkd 1978; 172: 440-4.

10 Feke GT, Green GJ, Goger DG, McMeel JW. Laser Doppler measurements of the effect of panretinal photocoagulation on retinal blood flow. Ophthalmology 1982; 89: 757-62.

11 Oswald B, Vilser W, Oswald H, Jutte A, Schweitzer D, Konigsdorffer E, et al. Measurement of flow-physiologic parameters of retinal blood circulation in type 1 and 2 parameters of retinal blood circulation in type 1 and 2 diabetics before and after photocoagulat

12 Grunwald JE, Riva CE, Brucker AJ, Sinclair SH, Petrig BL. Effect of panretinal photocoagulation on retinal blood flow in proliferative diabetic retinopathy. Ophthalmology 1986; 93: 590-5.

13 Wilson CA, Stefánsson E, Klombers L, Hubbard LD, Kaufman SC, Ferris FL. Optic disk neovascularization and retinal vessel diameter in diabetic retinopathy. $A m \mathcal{F}$ Ophthalmol 1988; 106: 131-4.

14 Grunwald JE, Brucker AJ, Petrig BL, Riva CE. Retinal blood flow regulation and the clinical response to panretinal photocoagulation in proliferative diabetic retinopathy. photocoagulation in proliferative

15 Patel V, Rassam S, Newsom R, Wiek J, Kohner E. Retinal blood flow in diabetic retinopathy. BMF 1992; 305: 678-83. 16 Feke GT, Goger DG, Tagawa H, Delori FC. Laser Doppler technique for absolute measurement of blood speed in retinal vessels. IEEE Trans Biomed Eng 1987; 34: 673-80.

17 Ogasawara H, Feke GT, Yoshida A, Milbocker MT, Weite JJ, McMeel JW. Retinal blood flow alterations associated with scleral buckling and encircling procedures. $\mathrm{Br} f$ Ophthalmol 1992; 76: 275-9.

18 Delori FC, Fitch KA, Feke GT, Deupree DM, Weiter JJ. Evaluation of micrometric and microdensitometric methods 
for measuring the width of retinal vessel images on fundus photographs. Graefes Arch Clin Exp Ophthalmol 1988; 226: 393-9.

19 Feke GT, Tagawa H, Deupree DM, Goger DG, Sebag J, Weiter JJ. Blood flow in the normal human retina. Invest Ophthalmol Vis Sci 1989; 30: 58-65.

20 Weiter JJ, Zuckerman R. The influence of the photoreceptorRPE complex on the inner retina. Ophthalmology 1980; 87: 1133-9.
21 Wise GN. Retinal neovascularisation. Trans Am Ophthalmol Soc 1956; 54: 729-826.

22 Vine AK. The efficacy of additional argon laser photocoagulation for persistent severe proliferative diabetic retinopathy. Ophthalmology 1985; 92: 1532-7.

23 Kaufman SC, Ferris FL, Seigel DG, Davis MD, Demets DL, DRS Research Group. Factors associated with visual outco Invest Ophthalmol Vis Sci 1989; 30: 23-8.

\section{History of ophthalmology}

\section{Notes from ophthalmic practice in the eighteenth century}

A review of the texts available in 1776 allows a fascinating mental step back in time, remembering that one would see patients in candle-lit private rooms, dressed in frock coat, buckled shoes, and periwig. Fees would be paid in silver or copper coinage in the capital, and possibly in chickens, pigs, or cloth in provincial surgeries. One would prescribe using either a quill pen, or possibly with one of the 'new' steel nibs. Presumably pharmacists, as now, were skilled in deciphering erratic writing.

(William Rowley wrote an interesting definition of the specialty in 1771 - 'ophthalmology is to assist in preserving the precious organ of vision, which is of utmost importance, and to relieve the injuries which that tender and sensible part is subject to.')

In the eighteenth century, most inflammatory conditions were diagnosed as 'ophthalmy'. James Ware preferred the term 'a blast in the eyes', however, and in speculating that 'it seemed to proceed from some peculiar property in the air around us', he comes within an ace of the principle of airborne bacterial infection.

After diagnosing a case of 'ophthalmy', various treatments could be chosen. Should one feel ill disposed towards the patient, frequent and violent purges were legitimate therapy. Hippocrates himself stated that 'flux of the lower belly cured ophthalmy', and certain writers in the 1700 s were quoting this with perfect seriousness. Rowley alone warns that 'purges of the drastic kind are highly improper'.

Opium was also used, applied locally or taken internally with wine, although James Ware, again quoting from the ancients, notes that Galen accidentally killed a gladiator by applying opium and warns against its use.

On the subject of bleeding, Ware and Rowley agreed on applying leeches to the temple, although they sometimes caused great swelling of the lids. Where leeches didn't work, Rowley advised bleeding in the arm, 'being sure to make a large orifice', whereas Ware preferred local bleeding and advised completely severing the temporal artery. He reported good results from this, stating that it cured by 'cutting off the source from which blood circulates to the inflamed part'.

The initial reasoning behind blood letting was presumably the noted association between 'disease' and 'reddening'. The interesting point is why logic dictated to the ancients that the influx of blood was 'bad'. Had they only reasoned that blood, being a life force, was entering the afflicted part to repair and cure, then they might not have tried it. Rowley described the surprisingly large number of tiny vessels visible in the inflamed eye with a magnifying glass, and in saying 'that the purpose cannot be commented on, even though cure cannot be claimed till the redness had gone', one feels he came near to questioning the practice.

Ware further advocated bleeding of the eye itself, by scraping the conjunctiva with a small brush made of barley beads - and he was one of the more humane, asserting that 'the popular solution of corrosive is a very torturing application!'.

An occupational history was taken in those days, and it was agreed that those 'forced by business to work much and late by candle light' should use solution of sublimate as a remedy. If this didn't help, then lotions of brandy and water or 'Sir Hans Sloane's ointment' were alternative measures.

Francis Geach, a Plymouth surgeon, firmly believed that ophthalmy had different causes in different weather. Those fortunate patients who attended him in warm or moist temperatures were relieved by 'wine internally and externally', perhaps with a little opium if they were lucky, whereas those who had caught their affliction from cold air had to submit to 'energetic bleeding and purging'. One wonders whether his patients ever caught on, and attended a different surgeon - or not at all - during cold spells?

FIONA ROMAN

Geach F. Observations on inflammation of the eyes. London: Law 1776: $1-5$.

Rowley W. An essay on the ophthalmia. London: Newberry, 1771: 4-11.

Ware J. Remarks on the ophthalmy, psorophthalmy and purulent eye. London: Dilly, 1786: 22-33. 